\title{
Exocrine and Endocrine Pancreatic Cancer pNX TNM Finding v7
}

National Cancer Institute

\section{Source}

National Cancer Institute. Exocrine and Endocrine Pancreatic Cancer pNX TNM Finding v7. NCl Thesaurus. Code C90296.

Exocrine or endocrine pancreatic cancer in which the regional lymph nodes cannot be assessed. (from AJCC 7th Ed.) 